\title{
Are the 'resident' dolphins of Doubtful Sound becoming less resident?
}

\author{
Shaun D. Henderson ${ }^{1,2, *}$, Stephen M. Dawson ${ }^{1}$, William Rayment ${ }^{1}$, \\ Rohan J. C. Currey ${ }^{1,3}$ \\ ${ }^{1}$ Department of Marine Science, University of Otago, Dunedin 9016, New Zealand \\ ${ }^{2}$ Department of Science and Engineering, Tacoma Community College, Tacoma 98466, USA \\ ${ }^{3}$ Ministry for Primary Industries, Wellington 6140, New Zealand
}

\begin{abstract}
Patterns of habitat use by wide-ranging animals may change in response to perturbations within their environment. In 2009, a group of 15 bottlenose dolphins, known to be part of the population in Doubtful Sound, New Zealand, were seen in another nearby fiord. This population has been closely monitored since 1990, and this was the first time that a group from Doubtful Sound was seen elsewhere. Since this first occurrence there have been at least 6 other occasions on which 'resident' dolphins were missing for at least $3 \mathrm{~d}$, to later reappear in the fiord. During these absences, the other members of the population were routinely sighted. We use capturerecapture modelling based on photo-ID data to demonstrate a dramatic difference in capture probability between 2005 to 2009 and 2010 to 2011 . Given the extremely high capture probability in the first period, and the fact that field effort has significantly increased from 2009 through to 2011, it is unlikely that these groups were within the fiord and simply missed. These findings suggest the possibility that the habitat use of this population has changed to include relatively frequent excursions beyond the fiord complex.
\end{abstract}

KEY WORDS: Bottlenose dolphins - Tursiops truncatus - Capture probability - Habitat · Range shift

\section{INTRODUCTION}

A population's range typically changes as biotic and abiotic factors within that area change (Holt 2003). For example, many species show predictable seasonal shifts in distribution (Wallace 2006, Rayment et al. 2010, Csepp et al. 2011). However, there can be abrupt, unexpected changes to a species' range driven by changes in climate, the arrival of competitors and/or anthropogenic environmental degradation (Holt 2003). Many such shifts have been linked to climate change. Parmesan \& Yohe (2003) conducted a global meta-analysis of more than 1700 species, showing range shift averaging $6.1 \mathrm{~km}$ per decade towards the poles. For cetaceans, Lambert et al. (2011) predicted a northern expansion of the range of short-beaked common dolphins Delphinus delphis in the north-east Atlantic due to increasing water temperatures. The arrival of new competitors or predators is often correlated with environmental perturbation. For example, a change in climate may open up new habitat which was previously out of reach to competitors (Dukes \& Mooney 1999).

Anthropogenic environmental degradation has caused a wide variety of species to shift their range (Holt 2003, Franco et al. 2006, Vila et al. 2008). Often it can lead to a loss or reduction of suitable habitat, such as when dams are built (Dudgeon 2000), but anthropogenic modification can also result in the enlargement of suitable habitat. For example, an increase in farmland and park area has made more habitat for white-tail deer in America (McCabe \& McCabe 1984). 
Changes in habitat use by bottlenose dolphins have been hypothesised to be in response to changes in prey availability, water temperature and tourism (Wells et al. 1990, Lusseau 2003, Wilson et al. 2004). Wilson et al. (2004) observed a drop in sighting rate of known subsets of the bottlenose dolphin population that had been considered resident within the inner Moray Firth, Scotland. These individuals appeared to have changed their habitat use to include the outer Moray Firth and exposed coastal areas, up to 400 miles (643.6 km) away. Wilson et al. (2004) hypothesised that these changes had most likely been driven by changes in prey resources.

The observation by Wilson et al. (2004) was only the second time that such a dramatic shift had been reported for dolphins. In 1982 to 1983, bottlenose dolphins in California changed their home range to include the northern Californian coast, 600 miles $(965.4 \mathrm{~km})$ away from the previous northern extent of their range (Wells et al. 1990). It was proposed that the expansion of their home range was due to warmwater incursion driven by an El Niño event. Interestingly, these dolphins continued to use the northern waters after the El Niño event. Wells et al. (1990) observed that this change underscored the behavioural flexibility of the species, and suggested that temperature increases could provide a mechanism to drive range expansion.

In Fiordland, New Zealand, there are 3 separate populations of bottlenose dolphins which show very different patterns of habitat use (Bräger \& Schneider 1998, Lusseau \& Slooten 2002). The 2 southern populations are resident in Dusky/Breaksea Sound and Doubtful Sound, respectively (Fig. 1). The northernmost population is more transient, occurring along the outer northern coast of Fiordland from Charles Sound to Lake McKerrow, and has been seen in all 7 of the northern fiords (Lusseau 2005). In the largest of the northern fiords, Milford Sound (Stanton \& Pickard 1981), they are seen regularly in winter but only rarely in summer (Lusseau 2005). This is contrary to what would be expected in terms of both water temperature and prey availability, but instead seems to be dependent on high vessel traffic in summer (Lusseau 2005).
Doubtful Sound $\left(45^{\circ} 30^{\prime} \mathrm{S}, 167^{\circ} 00^{\prime} \mathrm{E}\right)$ is the second largest of the 14 fiords in Fiordland (Stanton \& Pickard 1981). The resident bottlenose dolphin population in this fiord declined by 34 to $39 \%$ in the $12 \mathrm{yr}$ preceding 2007 (Currey et al. 2007) and has recently been classified as Critically Endangered under the IUCN Red List's regional criteria (Currey et al. 2009a, 2011b). In 2009, a group of 15 bottlenose dolphins, known to be resident in Doubtful Sound (Schneider 1999, Currey et al. 2007, Rowe et al. 2010), was photographed in another fiord for the first time (photographed by Department of Conservation [DOC] workers and verified by University of Otago researchers). Since this first sighting of a group away from Doubtful Sound, the number of occasions on which groups were missing from the fiord has increased in frequency. This implies a change in habitat use and/or an extension of the population's range.

We present an analysis of sighting records generated from photo-ID surveys to determine if the fre-

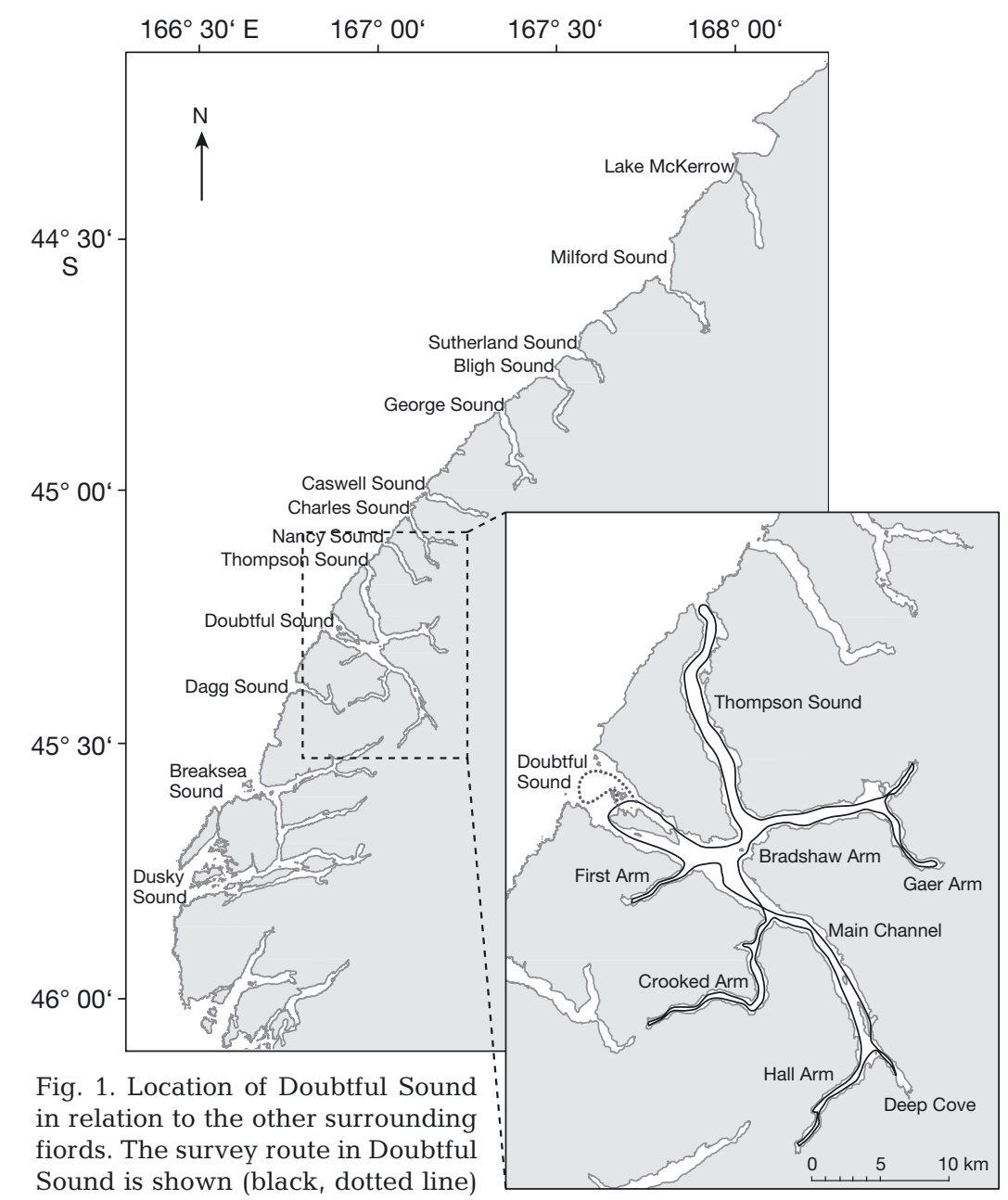


quency with which dolphins are absent from Doubtful Sound has increased. Our study has implications for researchers needing to draw inferences from systematic surveys on which the target animals are not detected. The results help to form hypotheses about environmental change and guide future research requirements.

\section{MATERIALS AND METHODS}

\section{Field effort}

Photo-ID surveys were conducted in Doubtful Sound between 2005 and 2011. Survey effort is summarised in Table 1, and includes only those days spent actively looking for dolphins for the purpose of conducting photo-ID. A survey trip is defined as a number of days of survey effort (often consecutive), closely grouped in time. Trips consisted of between 5 and $23 \mathrm{~d}$ of survey effort (mean $=7.4 \mathrm{~d}$ ) and were separated by at least $19 \mathrm{~d}$ (mean $=74.8 \mathrm{~d})$. Systematic photo-ID surveys started and ended in Deep Cove, following a pre-determined route established by Schneider (1999) (Fig. 1). The principal research vessel used was a $5 \mathrm{~m}$ aluminium-hulled vessel, powered by a $60 \mathrm{hp} 4$-stroke outboard engine.

Surveys began as soon as available light permitted photography, and the survey route (tracked by Garmin 60CSX GPS storing a fix every 15 s) was followed until a group of dolphins was encountered. A group was defined as any number of dolphins within approximately 5 body lengths of each other, closely associating and engaged in similar activities (Constantine et al. 2004). In an attempt to standardise photographic effort, each group was photographed until it was believed that approximately 4 photos were obtained per group member (Würsig \& Jefferson 1990), at which point the survey route was continued until the route was completed, or light/ weather conditions became unworkable (i.e. Beaufort $\geq 4$ or heavy rain). Photographs of marked dolphins were compared to a catalogue established in 1993 (Schneider 1999). All individuals in the Doubtful Sound population over 3 yr old are recognisable, due to the accumulation of nicks in the dorsal fin (Currey et al. 2009b). As the population has been studied intensively since 1990 (Williams et al. 1993), the age of many individuals is known precisely, and the sex of all individuals over $3 \mathrm{yr}$ old has been established via direct observation of the genital area (Currey et al. 2009b).

\section{Capture probability}

Capture probability of dolphins in Doubtful Sound was estimated by compiling capture histories of individuals per trip. Estimates of capture probability are potentially influenced by the level of survey effort. We standardised the level of effort so that differences in estimated capture probabilities among trips could be attributed to differences in residency of individual dolphins. Sighting records for each trip were standardised by search effort using 2 methods, (1) reflecting distance surveyed and (2) reflecting time spent in the field:

(1) The total distance surveyed for each trip between 2005 and 2011 was estimated from the GPS tracks. The minimum distance surveyed was 280 nautical miles ( $\mathrm{n}$ miles) over a $7 \mathrm{~d}$ trip in December 2008. This distance was therefore used as the standard unit of effort for all trips. Individuals were classified as present (1 in the capture history) if they were sighted during the first $280 \mathrm{n}$ miles of a particular trip, and absent ( 0 in the capture history) if they were not. 
(2) Between 2005 and 2011, the minimum duration of survey effort per trip was $5 \mathrm{~d}$. Individuals sighted during the first $5 \mathrm{~d}$ of each trip were classified as present, and otherwise classified as absent.

For each method of quantifying field effort, the programme MARK (White \& Burnham 1999) was used to analyse the series of capture histories because it offered a powerful and convenient modelling framework which estimated capture probability and its precision. Capture probability $\left(p_{\mathrm{a}}\right)$ and apparent survival $\left(\phi_{\mathrm{a}}\right)$ were modelled using the Cormack-JollySeber (CJS) capture-recapture method (Cormack 1964, Jolly 1965, Seber 1965) and estimated for each survey trip. For this analysis, only individuals known to be at least 3 yr old were included. 'Adult' survival rate for this population has been shown to be extremely high (0.937, 95\% CI: 0.9170 to 0.9530; Currey et al. 2009b). Survival rates were fixed to be time invariant so that changes in model weight would be due to changes in capture probability. Models were constructed to assess whether there was evidence for time-based variation in $p_{\mathrm{a}}$ among survey trips over the course of the study, while holding survival as a single estimate spanning the study period. Following the approach of Currey et al. (2009b), we constructed models corresponding to 5 hypotheses: (1) a single estimate of $p_{\mathrm{a}}$ spanning the study period ( $\left.p_{\mathrm{a}}().\right),(2)$ estimates of $p_{\mathrm{a}}$ fluctuating from trip to trip ( $\left.p_{\mathrm{a}}\left(t_{\text {trip }}\right)\right)$, (3) estimates of $p_{\mathrm{a}}$ fluctuating from year to year $\left(p_{\mathrm{a}}\left(t_{\text {year }}\right)\right)$, (4) a shift in $p_{\mathrm{a}}$ in $2010\left(p_{\mathrm{a}}\left(t_{2010}\right)\right)$, when the population's previous decline halted, and (5) a monotonic decrease in $p_{\mathrm{a}}$ using a cumulative logit link function to reflect a decrease in $p_{\mathrm{a}}$ in any year or across multiple years $\left(p_{\mathrm{a}}\left(t_{\mathrm{CLdecrease}}\right)\right.$. Model goodness-of-fit was assessed using the bootstrap simulation procedures provided in MARK (White \& Burnham 1999). To assist in interpreting the strength of support for competing models, evidence ratios were calculated (Anderson 2008). Model-averaged estimates of annual $p_{\mathrm{a}}$ were produced to reflect the corrected Akaike's information criterion $\left(\mathrm{AIC}_{\mathrm{C}}\right)$ weight of the candidate models (Burnham \& Anderson 2002).

\section{RESULTS}

Between 2005 and 2011, there were 6 instances when a group of dolphins was not found within the fiord over several days, despite thorough searching in good conditions (Table 2). All instances occurred from 2009 on- wards. Missing groups often had similar numbers of males and females. Also, they usually included subadults and calves of the year (Table 2). Every individual in the population was missing on at least 1 occasion, with an average of 3.55 (SE: 0.28) absences over the 7 occasions. No individual was missing every time. Estimates of the length of time that groups were absent (Table 2) are probably biased low, because on all occasions, these groups were missing from the very start of a field trip or were missing for the whole survey trip. Therefore, the estimates of time absent are minima. All individuals were sighted again in Doubtful Sound following a period of absence.

Capture-recapture analysis using minimum survey distance to define the length of the trip showed the best model was change in capture probability in 2010 (Table 3). This model was 10 times more likely than capture probability fluctuating from trip-to-trip, and 10.6 times more likely than capture probability fluctuating from year to year. Evidence ratios of this magnitude indicate relatively weak support for the best model over the others (Anderson 2008). Modelaveraged estimates of capture probability were consistently high (>0.95) from 2005 to 2009 and then declined significantly in 2010 and 2011 (Fig. 2). Model results using the minimum trip duration to standardise the trips resulted in the same order of model preference as with the previous method (Table 4), and both approaches showed a significant drop in capture probability in 2010 and 2011 (Fig. 2). Capture probabilities were significantly higher in 2010 and 2011 for the models in which effort was standardised by trip duration.

The area surveyed per day from 2009 to 2011 increased significantly compared to previous years (Kruskal-Wallis test: $H(1, \mathrm{~N}=229)=44.254, \mathrm{p}<$ 0.001; Fig. 3). From 2005 through 2011, there were 2 different primary researchers (2004 to 2008 R. J. C.

Table 2. Groups of dolphins missing during trips into Doubtful Sound. The number of days is not given for the November 2009 group as this group was photographed in Dagg Sound by Department of Conservation staff. No. of ind. missing refers to the number of individuals missing during the survey trip

\begin{tabular}{|lcccccc|}
\hline & Nov 09 & Jul 10 & Dec 10 & Mar 11 & Aug 11 & Oct 11 \\
\hline No. of ind. missing & 15 & 9 & 25 & 47 & 6 & 43 \\
No. of days missing & - & 4 & 3 & 3 & 6 & 7 \\
No. of males & 10 & 4 & 11 & 22 & 5 & 18 \\
No. of females & 5 & 5 & 10 & 20 & 1 & 18 \\
No. of adults & 14 & 8 & 20 & 39 & 6 & 34 \\
No. of sub-adults & 1 & 1 & 1 & 5 & 0 & 5 \\
No. of calves & 0 & 0 & 4 & 3 & 0 & 4 \\
\% of calves missing & 0 & 0 & 50 & 60 & 0 & 67 \\
\hline
\end{tabular}


Table 3. Model ranking of Cormack-Jolly-Seber capture-recapture models estimating apparent capture probability $\left(p_{\mathrm{a}}\right)$ and survival $\left(\phi_{a}\right)$ for adult bottlenose dolphins observed in Doubtful Sound from 2005 to 2011, using minimum trip survey distance to standardise sightings. ER (evidence ratio) is the relative likelihood of the model compared with the most parsimonious model. AICc: corrected Akaike's information criterion

\begin{tabular}{|lcccccc|}
\hline Model & $\mathrm{AIC}_{\mathrm{c}}$ & $\Delta \mathrm{AIC}_{\mathrm{c}}$ & $\mathrm{AIC}_{\mathrm{c}}$ weight & Likelihood & Parameters & Deviance \\
\hline$p_{\mathrm{a}}\left(t_{2010}\right) \phi_{\mathrm{a}}()$. & 428.17 & 0.00 & 0.8356 & 1.00 & 3 & 192.11 \\
$p_{\mathrm{a}}\left(t_{\text {trip }}\right) \phi_{\mathrm{a}}()$. & 432.78 & 4.60 & 0.0836 & 0.10 & 8 & 184.61 \\
$p_{\mathrm{a}}\left(t_{\text {year }}\right) \phi_{\mathrm{a}}()$. & 432.90 & 4.73 & 0.0786 & 0.09 & 24 & 139.42 \\
$p_{\mathrm{a}}\left(t_{\text {CLyear }}\right) \phi_{\mathrm{a}}()$. & 440.01 & 11.84 & 0.0022 & 0.00 & 9 & 201.94 \\
$\left.p_{\mathrm{a}}(.) \phi_{\mathrm{a}}\right) \phi_{\mathrm{a}}()$. & 467.51 & 39.34 & 0.0000 & 0.00 & 2 & 233.46 \\
\hline
\end{tabular}

Table 4. Model ranking of Cormack-Jolly-Seber capture-recapture models estimating apparent capture probability $\left(p_{\mathrm{a}}\right)$ and survival $\left(\phi_{a}\right)$ for adult bottlenose dolphins observed in Doubtful Sound from 2005 to 2011, using minimum trip duration to standardise sightings. ER (evidence ratio) is the relative likelihood of the model compared with the most parsimonious model.

AICc: corrected Akaike's information criterion

\begin{tabular}{|lcccccc|}
\hline Model & $\mathrm{AIC}_{\mathrm{c}}$ & $\Delta \mathrm{AIC}_{\mathrm{c}}$ & $\mathrm{AIC}_{\mathrm{c}}$ weight & Likelihood & Parameters & Deviance \\
\hline$p_{\mathrm{a}}\left(t_{2010}\right) \phi_{\mathrm{a}}()$. & 390.31 & 0.00 & 0.6032 & 1.00 & 3 & 172.15 \\
$p_{\mathrm{a}}\left(t_{\text {trip }}\right) \phi_{\mathrm{a}}()$. & 391.29 & 0.98 & 0.3699 & 0.61 & 31 & 115.72 \\
$p_{\mathrm{a}}\left(t_{\text {year }}\right) \phi_{\mathrm{a}}()$. & 396.53 & 6.22 & 0.0269 & 0.04 & 9 & 166.26 \\
$p_{\mathrm{a}}\left(t_{\mathrm{CLyear}}\right) \phi_{\mathrm{a}}()$. & 415.94 & 25.63 & 0.0000 & 0.00 & 11 & 181.61 \\
$\left.p_{\mathrm{a}}(.) \phi_{\mathrm{a}}\right) \phi_{\mathrm{a}}()$. & 421.08 & 30.77 & 0.0000 & 0.00 & 2 & 22.4 \\
\hline
\end{tabular}

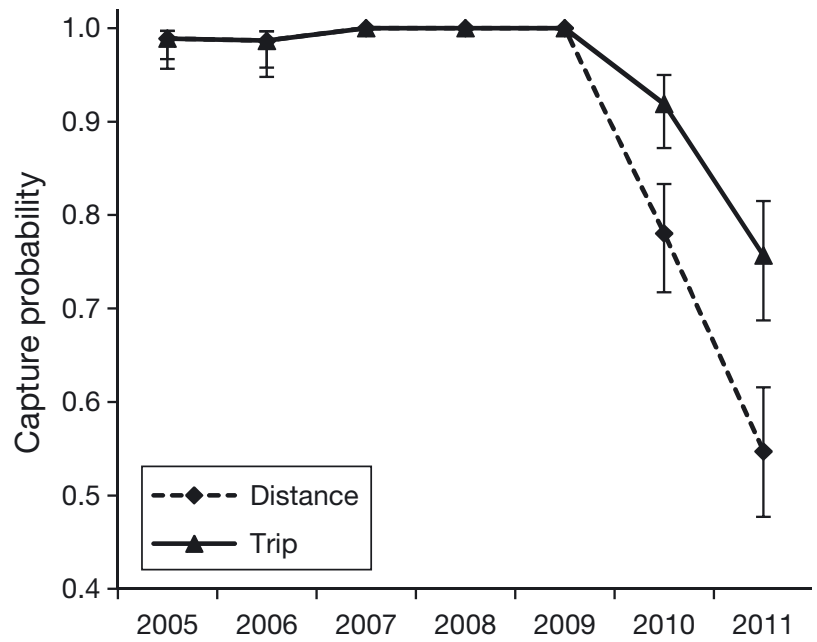

Fig. 2. Tursiops truncates. Model-averaged estimates of apparent annual capture probability $\left(p_{\mathrm{a}}\right)$ for bottlenose dolphin adults observed in Doubtful Sound, from 2005 through 2011. Trip length has been standardised by survey distance (Distance) and survey duration (Trip). Estimates were derived using Cormack-Jolly-Seber capture-recapture models. Error bars are $95 \%$ confidence intervals that account for both parameter and model uncertainty

Currey, and 2009 to 2011 S. D. Henderson). The same survey methodology was followed; however, from 2009 to 2011, a change in research focus meant that more effort was made to continue searching after a large group of dolphins had been encountered.

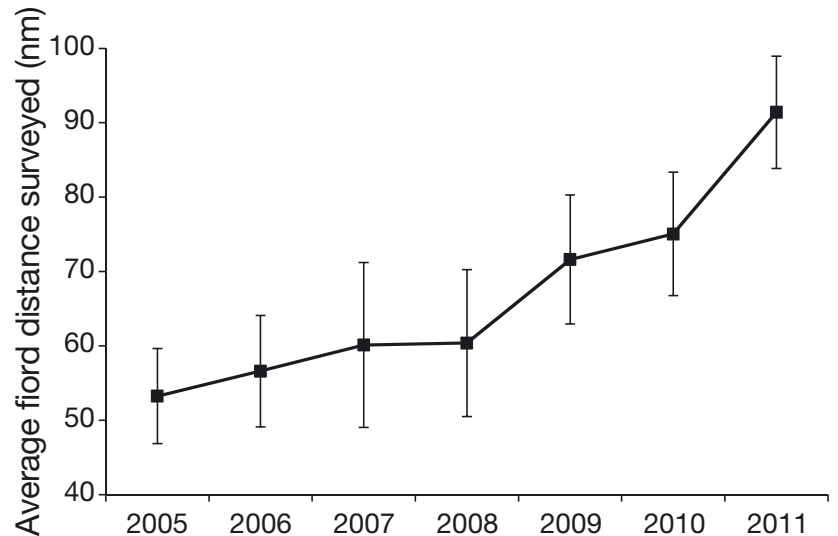

Fig. 3. Average daily distance in nautical miles (nm) within the fiord surveyed in Doubtful Sound from 2005 through 2011. Error bars are $\pm 1 \mathrm{SE}$

\section{DISCUSSION}

Each approach to standardising effort reflects certain assumptions about the best search tactic. Using the minimum distance covered during a trip assumes that the most important factor is finding a group of dolphins and staying with them. Using trip duration as an effort measure assumes that it is irrelevant how much distance is covered because the dolphins move around, and so the more days on the water the more likely the researcher is to see every dolphin in the 
population. This measure of effort would suit fissionfusion societies (Connor et al. 2000), in which individuals associate in small groups in which composition changes very dynamically, often several times per day (White 1992). Yet, within these groups there are often strong associations which can be maintained for years (Shane et al. 1986, Lusseau et al. 2003, Rogers et al. 2004). In our study, capture probabilities in 2010 and 2011 were significantly higher for the models in which effort was standardised by trip duration. This suggests that dolphin groups are moving around the fiord and individuals are more likely to be photographed if researchers spend more time in the field. Nonetheless, both methods of standardising effort resulted in very high capture probabilities (>0.95) up until 2009, indicating that each trip was saturated in terms of search effort while dolphins were effectively resident in Doubtful Sound. Furthermore, both methods indicated a decline in capture probability after 2009 and the respective model rankings were identical. Hence, choosing one method of standardising effort over another would not affect the conclusions of the study.

In any capture-recapture study, failure to sight an individual can mean 1 of 4 things: (1) the individual died, (2) the individual was present but was misidentified, (3) the individual temporarily or permanently emigrated out of the survey area, or (4) the individual was within the survey area but was missed. In the case of non-sighting of groups (Table 2), the individuals in question had not died or permanently emigrated because in all cases they were seen again in Doubtful Sound after the period(s) of absence. Individuals are unlikely to be mis-identified as photo-ID protocols are strict (Williams et al. 1993), the catalogue is updated after every survey trip, and the small population size (56, coefficient of variance $[\mathrm{CV}]=1.0 \%$, Currey et al. 2007) coupled with very high field effort has allowed even subtly marked animals to be uniquely identified (Currey et al. 2007). This leaves 2 of the above explanations as most likely: the individuals either temporarily left the survey area, or were in the study area but were missed. It is accepted that small groups may be missed during the course of a normal day's survey. However, it is unlikely that larger groups would be missed for several consecutive days while the other members of the population are being sighted. A review of the sighting history, for the whole long-term monitoring project (1994-2012), showed only 3 prior instances of a group of $\geq 5$ individuals missing for more than 3 consecutive days while the other members of the population were being consistently sighted. Also, the very high per-trip capture probability between 2005 and 2009 suggests that individuals were rarely missed if they were present. Considering that survey effort increased significantly over the course of the study period, it seems that the likelihood of consistently missing a subset of dolphins is extremely low. Furthermore, there were no changes in survey methodology or photographers at the time of the decline in capture probability.

We conclude, therefore, that the decline in capture probability is most likely caused by temporary emigration of individuals from Doubtful Sound. This conclusion is strengthened by recent incidental observations of bottlenose dolphins leaving Doubtful Sound, and of Doubtful Sound 'residents' being present in other fiords. For example, on one occasion, the dolphins were seen in another fiord by DOC staff who provided photos to corroborate the sighting, and on 2 occasions in 2011, we witnessed large groups moving out of Thompson Sound and heading up the coast (S. D. Henderson unpubl. data). The dolphins temporarily absent from Doubtful Sound often made up a large proportion of a population previously considered to be resident. For example, 47 individuals were not sighted for $3 \mathrm{~d}$ in March 2011, representing $77 \%$ of the estimated total abundance at that time (61, $\mathrm{CV}=1.46 \%$; S. D. Henderson unpubl. data).

In other populations of bottlenose dolphins, adult males travel more widely than females and juveniles (Scott et al. 1990). This was not the case in our study. The groups believed to have left the fiord were a mix of ages and sexes, including mothers with neonate calves on 4 of 8 occasions. Furthermore, these groups did not consistently comprise the same individuals. Every individual in the population was a member of at least 1 of these absent groups, yet no individual was away on all the trips. While not witnessed in cetacean populations, group ranging in primates is often a prelude to group fission; a specific group starts ranging away from the primary population before the split occurs (Janmaat et al. 2009). As every member of the Doubtful Sound population has ranged away from the fiord at some point between 2009 and 2012, there is no evidence that a discrete group is about to split from the population.

While this may be a case of range expansion, what we can say with more certainty is that the dolphins have increased the frequency with which they temporarily emigrate from Doubtful Sound. This raises 2 important questions: where are they going, and why are they leaving the fiord more frequently? To determine where they are going, more intensive monitoring of the other fiords is needed. 
As regards the second question, dolphin residency in Milford Sound is related to the number of tour boats operating on the fiord (Lusseau 2005). In Doubtful Sound, commercial tour boat interactions with dolphins have been demonstrated to alter the behavioural budget of the dolphins, and females in particular suffer higher biological cost of interactions (Lusseau 2003). The Doubtful Sound dolphins could be leaving the fiord to avoid vessel traffic. Yet the timing of the absences does not match the seasonal peak of vessel activity. Also, the total number of vessels offering sight-seeing tours declined from 9 vessels and 2 sea kayaking companies in 2002 (Lusseau \& Slooten 2002), to 6 vessels and 2 kayak companies in 2012 (DOC unpubl. data). Further, in 2008, the DOC established dolphin protection zones in areas regularly used by dolphins. While there are currently no data on the number of dolphin-tour boat interactions, it is likely that the frequency of interactions has declined. If so, this suggests that avoidance of tourism is not the cause of the recent change in residency of this population (cf. Bejder et al. 2006). This is a valuable, cautionary note, given near-inexorable increases in nature-based tourism globally. Strictly, unequivocally attributing causes of change in the ecology of long-lived animals requires appropriate levels of experimental control. This is often not possible in wild populations. Nevertheless, caution is urged when population responses may be coincident with assumed impacts, rather than caused by them.

Range expansion in populations of bottlenose dolphins has been linked with water temperature fluctuations (Wells et al. 1990, Lambert et al. 2011). The Manapouri power station has a freshwater discharge within Doubtful Sound that has tripled the natural freshwater inflow into the fiord (Gibbs et al. 2000, Gibbs 2001). This freshwater layer is colder than the underlying seawater from June to November (Gibbs 2001). The power station has been operational since 1969. Flow data from the power station's operators show no convincing evidence of consistently increased flow in 2010 and 2011 as opposed to 1999-2009 (when flow data first became available; Meridian Energy unpubl. data). New Zealand was in a La Niña phase of the Southern Oscillation Index (SOI) for 2010 and 2011 (Australian Bureau of Meteorology 2012). During La Niña years, the Fiordland coastal waters are warmer and there is less rainfall (Mullan 1996), which may have triggered some direct or indirect change.

Wilson et al. (2004) suggested that range expansion by bottlenose dolphins in the Moray Firth, Scotland, may be due to variations in prey availability. In Doubtful Sound, dolphins are reliant on demersal and reef-associated fish prey (Lusseau \& Wing 2006). Local changes in this prey resource could result in dolphins having to range further, and outside of the fiord, in order to meet their energetic requirements. Past fishing practices have resulted in declines of commercially important fish species in Doubtful Sound (e.g. Beentjes \& Carbines 2005), and the input of freshwater from the Manapouri power station has led to significant ecological changes within the fiord (e.g. Boyle et al. 2001, Tallis et al. 2004, Rutger \& Wing 2006). Further work on trends in availability of bottlenose dolphin prey species in Doubtful Sound would be required to test this hypothesis.

Currey et al. (2007) detected a decline in abundance of 34 to $39 \%$ in the 12 years preceding 2007 . The population has since increased, but age-structured, stochastic projection models suggest that, long term, the decline is most likely to continue $(60 \%$ of model runs declined; S. D. Henderson unpubl. data). All the dolphins which were observed to be temporarily absent from Doubtful Sound during this study, and therefore contributed to the decrease in estimated capture probability, have been sighted again in the fiord. Therefore, permanent emigration is unlikely to be a causal factor in the population's decline. Instead, Currey et al. (2009a, 2011a) identified a decline in calf survival (0 to $1 \mathrm{yr}$ of age) after 2001 and a decline in the survival of juveniles (1 to $3 \mathrm{yr}$ of age) prior to 2001 as being the most likely explanation for the trend of decreasing abundance.

Clearly, monitoring of the dolphin population of Doubtful Sound should continue, ideally including regular surveys of areas outside the fiord. For the current photo-ID monitoring, the effort analyses suggest that it is more important to have longer trips even if all the fiord area is not covered. However, it remains evident that only by surveying the whole fiord can it be ascertained that dolphins which are not photographed are truly missing.

Our study has wider implications for research on mobile species sensitive to environmental change. We have shown that mark-recapture analyses can be used to quantify differences in residency patterns over time, and that reliably documenting absences is an important component of ecological research. Furthermore, we are able to make inferences concerning the use of habitats outside the areas surveyed. While we are not able to identify the causal factor(s) behind changes in residency, this kind of study is useful in shaping hypotheses about changes in habitat use and in guiding future research. 
Acknowledgements. This study builds on the long-term population monitoring in Doubtful Sound undertaken by the University of Otago Marine Mammal Research Group. We thank those who have contributed to this project over the years: Dr. L. Slooten, J. Williams, Dr. K. Schneider, P. Haase, Dr. D. Lusseau, Dr. O. Boisseau and L. Rowe. The New Zealand Whale and Dolphin Trust, and Marine Mammal Viewing Permit Levy Group supplied research equipment and funding. We thank the group at the DOC Te Anau: K. Blakemore, R. Kinsey, D. Johnson, P. Young and M. Peychers for making this collaborative project between the DOC and the Otago Marine Mammal Research Group possible.

\section{LITERATURE CITED}

Anderson DR (2008) Model based inference in the life sciences: A primer on evidence. Springer, New York, NY

Australian Bureau of Meteorology (2012) S.O.I. (Southern Oscillation Index) archives - 1876 to present. www.bom. gov.au/climate/current/soihtm1.shtml

Beentjes MP, Carbines GD (2005) Population structure and relative abundance of blue cod (Parapercis colias) off Banks Peninsula and in Dusky Sound, New Zealand. NZ J Mar Freshw Res 39:77-90

Bejder L, Samuels A, Whitehead H, Gales N and others (2006) Decline in relative abundance of bottlenose dolphins exposed to long-term disturbance. Conserv Biol 20: 1791-1798

Boyle MC, Jillett JB, Mladenov PV (2001) Intertidal communities in Doubtful Sound, New Zealand: changes over time. NZ J Mar Freshw Res 35:663-673

Bräger S, Schneider K (1998) Near-shore distribution and abundance of dolphins along the west coast of the South Island, New Zealand. NZ J Mar Freshw Res 32: 105-112

Burnham KP, Anderson DR (2002) Model selection and multimodel inference: a practical information-theoretic approach. Springer Verlag, Berlin

Connor RC, Wells RS, Mann J, Read AJ (2000) The bottlenose dolphin. Social relationships in a fission-fusion society. In: Mann J, Connor R, Tyack PL, Whitehead H (eds) Cetacean societies: Field studies of dolphins and whales. University of Chicago Press, Chicago, IL, p 91-125

Constantine R, Brunton DH, Dennis T (2004) Dolphinwatching tour boats change bottlenose dolphin (Tursiops truncatus) behaviour. Biol Conserv 117:299-307

Cormack R (1964) Estimates of survival from the sighting of marked animals. Biometrika 51:429-438

> Csepp DJ, Vollenweider JJ, Sigler MF (2011) Seasonal abundance and distribution of pelagic and demersal fishes in southeastern Alaska. Fish Res 108:307-320

Currey RJC, Dawson SM, Slooten E (2007) New abundance estimates suggest Doubtful Sound bottlenose dolphins are declining. Pac Conserv Biol 13:265-273

> Currey RJC, Dawson SM, Slooten E (2009a) An approach for regional threat assessment under IUCN Red List criteria that is robust to uncertainty: The Fiordland bottlenose dolphins are critically endangered. Biol Conserv 142: 1570-1579

- Currey RJC, Dawson SM, Slooten E, Schneider K and others (2009b) Survival rates for a declining population of bottlenose dolphins in Doubtful Sound, New Zealand: an information theoretic approach to assessing the role of human impacts. Aquat Conserv 19:658-670
Currey RJC, Dawson SM, Schneider K, Lusseau D, Boisseau OJ, Haase P, Slooten E (2011a) Inferring causal factors for a declining population of bottlenose dolphins via temporal symmetry capture-recapture modeling. Mar Mamm Sci 27:554-566

Currey RJC, Dawson SM, Slooten E (2011b) Tursiops truncatus (Fiordland subpopulation). In: IUCN 2012. IUCN Red List of Threatened Species. Version 2012.1. www. iucnredlist.org (accessed 20 August 2012)

> Dudgeon D (2000) Large-scale hydrological changes in tropical Asia: Prospects for riverine biodiversity. Bioscience 50:793-806

> Dukes JS, Mooney HA (1999) Does global change increase the success of biological invaders? Trends Ecol Evol 14: 135-139

Franco A, Hill JK, Kitschke C, Collingham YC and others (2006) Impacts of climate warming and habitat loss on extinctions at species' low latitude range boundaries. Glob Change Biol 12:1545-1553

Gibbs MT (2001) Aspects of the structure and variability of the low-salinity-layer in Doubtful Sound, a New Zealand fiord. NZ J Mar Freshw Res 35:59-72

Gibbs MT, Bowman MJ, Dietrich DE (2000) Maintenance of near-surface stratification in Doubtful Sound, a New Zealand fjord. Estuar Coast Shelf Sci 51:683-704

Holt RD (2003) On the evolutionary ecology of species' ranges. Evol Ecol Res 5:159-178

> Janmaat KRL, Olupot W, Chancellor RL, Arlet ME, Waser PM (2009) Long-term site fidelity and individual home range shifts in Lophocebus albigena. Int J Primatol 30: 443-466

> Jolly GM (1965) Explicit estimates from capture-recapture data with both death and immigration-stochastic model. Biometrika 52:225-247

> Lambert E, MacLeod CD, Hall K, Brereton T and others (2011) Quantifying likely cetacean range shifts in response to global climatic change: implications for conservation strategies in a changing world. Endang Species Res 15:205-222

> Lusseau D (2003) Male and female bottlenose dolphins Tursiops spp. have different strategies to avoid interactions with tour boats in Doubtful Sound, New Zealand. Mar Ecol Prog Ser 257:267-274

Lusseau D (2005) Residency pattern of bottlenose dolphins Tursiops spp. in Milford Sound, New Zealand, is related to boat traffic. Mar Ecol Prog Ser 295:265-272

Lusseau D, Slooten E (2002) Cetacean sightings off the fiordland coastline: analysis of commercial marine mammal viewing data 1996-99. Science for Conservation 187. Department of Conservation, Wellington

> Lusseau SM, Wing SR (2006) Importance of local production versus pelagic subsidies in the diet of an isolated population of bottlenose dolphins Tursiops sp. Mar Ecol Prog Ser 321:283-293

> Lusseau D, Schneider K, Boisseau OJ, Haase P, Slooten E, Dawson SM (2003) The bottlenose dolphin community of Doubtful Sound features a large proportion of longlasting associations. Behav Ecol Sociobiol 54:396-405

McCabe RE, McCabe TR (1984) Of slings and arrows: an historical retrospection. White-tailed deer ecology and management. Stackpole Books, Harrisburg, PA

Mullan B (1996) Effects of ENSO on New Zealand and the South Pacific. In: Braddock D (ed) Prospects and needs for climate forecasting. Miscellaneous Series 34. Royal Society of New Zealand, Wellington, p 23-27 
Parmesan C, Yohe G (2003) A globally coherent fingerprint of climate change impacts across natural systems. Nature 421:37-42

Rayment W, Dawson S, Slooten E (2010) Seasonal changes in distribution of Hector's dolphin at Banks Peninsula, New Zealand: Implications for protected area design. Aquat Conserv 20:106-116

Rogers CA, Brunnick BJ, Herzing DL, Baldwin JD (2004) The social structure of bottlenose dolphins, Tursiops truncatus, in the Bahamas. Mar Mamm Sci 20:688-708

Rowe LE, Currey RJC, Dawson SM, Johnson D (2010) Assessment of epidermal condition and calf size of Fiordland bottlenose dolphin Tursiops truncatus populations using dorsal fin photographs and photogrammetry. Endang Species Res 11:83-89

Rutger SM, Wing SR (2006) Effects of freshwater input on shallow-water infaunal communities in Doubtful Sound, New Zealand. Mar Ecol Prog Ser 314:35-47

Schneider K (1999) Behaviour and ecology of bottlenose dolphins in Doubtful Sound, Fiordland, New Zealand. PhD thesis, University of Otago

Scott M, Wells R, Irvine A (1990) A long-term study of bottlenose dolphins on the west coast of Florida. In: Leatherwood S, Reeves R (eds) The bottlenose dolphin. Academic Press, San Diego, CA, p 235-244

Seber GAF (1965) A note on the multiple-recapture census. Biometrika 52:249-259

Shane SH, Wells RS, Wursig B (1986) Ecology, behavior and social organization of the bottlenose dolphin: a review. Mar Mamm Sci 2:34-63

Stanton B, Pickard GL (1981) Physical oceanography of the New Zealand fiords. NZ Oceanogr Inst Mem 88

Editorial responsibility: Robert Harcourt, Sydney, New South Wales, Australia
Tallis H, Wing S, Frew R (2004) Historical evidence for habitat conversion and local population decline in a New Zealand fjord. Ecol Appl 14:546-554

Vila A, Beade M, Barrios Lamunière D (2008) Home range and habitat selection of pampas deer. J Zool (Lond) 276 : 95-102

> Wallace RB (2006) Seasonal variations in black-faced black spider monkey (Ateles chamek) habitat use and ranging behavior in a southern Amazonian tropical forest. Am J Primatol 68:313-332

Wells R, Hansen L, Baldridge A, Dohl T, Kelly D, Defran R (1990) Northward extension of the range of bottlenose dolphins along the California coast. In: Leatherwood S, Reeves R (eds) The bottlenose dolphin. Academic Press, San Diego, CA, p 421-431

White FJ (1992) Pygmy chimpanzee social organization: variation with party size and between study sites. Am J Primatol 26:203-214

White GC, Burnham KP (1999) Program MARK: survival estimation from populations of marked animals. Bird Study 46:S120-S139

> Williams JA, Dawson SM, Slooten E (1993) The abundance and distribution of bottlenosed dolphins (Tursiops truncatus) in Doubtful Sound, New Zealand. Can J Zool 71: 2080-2088

Wilson B, Reid RJ, Grellier K, Thompson PM, Hammond PS (2004) Considering the temporal when managing the spatial: a population range expansion impacts protected areas-based management for bottlenose dolphins. Anim Conserv 7:331-338

Würsig B, Jefferson TA (1990) Methods of photo-identification for small cetaceans. Rep Int Whal Comm 12:43-52

Submitted: August 22, 2012; Accepted: November 29, 2012 Proofs received from author(s): February 26, 2013 